\title{
An Empirical Study of Students' Intention to Use Cloud E-Learning in Higher Education
}

https://doi.org/10.3991/ijet.v15i09.11867

\author{
Lillian-Yee-Kiaw Wang $(\bowtie)$ \\ Monash University Malaysia, Selangor, Malaysia \\ lillianwyk@gmail.com \\ Sook-Ling Lew, Siong-Hoe Lau \\ Multimedia University, Melaka, Malaysia
}

\begin{abstract}
Technological progress has resulted in constant change of social structures and led to continuous evolution of attitudes and values. Thus, a timely and comprehensive integrated technology acceptance framework was established, and factors predicting intention to use Cloud e-learning were empirically identified. A total of 11 determinants from varying sources of IS success, learning object criteria, technology acceptance, motivations, social cognitive, and expectancy values were unified and analysed in an integrated manner. The target population for this study was a group of IT students in a private university in southern region Malaysia. The results obtained from this study observed that content quality, pedagogical quality, perceived usefulness, social influence, attainment value, and utility value significantly predict intention to use Cloud elearning. By integrating IS success, learning object criteria, technology acceptance, motivations, social cognitive, and expectancy values into a single framework, new insights on Cloud e-learning acceptance in higher education can be attained.
\end{abstract}

Keywords - Intention to use, Cloud e-learning, structural equation modelling; empirical study

\section{Introduction}

Resulting from the swiftly evolving digital technologies, e-learning has been technologically advanced over the years. E-learning supports learning processes with information and communication technology (ICT) through the Internet, and Internet technology has been extensively used as an intermediate to design, implement and support learning processes, especially in higher education. With the evolution of ICT, many higher education institutions (HEIs) have migrated from conventional learning methods into upgraded e-learning processes [1]. To support such progression, HEIs must have adequate ICT infrastructures and huge investments, and this poses a challenge to many universities in providing advanced ICT services for their academics and students [2][3]. 
Cloud computing has appeared to be a promising solution to the challenges associated with reducing ICT costs [4]. The use of Cloud based applications is increasing among HEIs [5]. The adoption of Cloud computing in e-learning is redefining ICT infrastructure in HEIs and infusing Cloud computing benefits such as scalability [6][7], reusability of learning content [4], and knowledge sharing in a global scale [4][8].

Cloud computing is no doubt an innovative solution to address the challenges of conventional e-learning, nevertheless there is no guarantee for the acceptance and adoption of such a technically advanced technology due to its complex migration process [9]. The willingness to accept and adopt a new technology is often influenced by various factors such as individual attributes, system characteristics, organization and social interactions. Thus, it is crucial to understand the factors of one's willingness to accept and adopt Cloud e-learning in HEIs. This has inspired more research on the technology acceptance for Cloud e-learning to be carried out to study how Cloud e-learning can be integrated and utilised in the context of higher education, how students respond to Cloud e-learning, and whether they are using Cloud e-learning in the expected ways. Thus, a timely framework is necessary to produce more accurate studies on technology acceptance of Cloud e-learning.

The objective of this study is to investigate the students' intention to use Cloud elearning in higher education. A comprehensive technology acceptance framework for Cloud e-learning will be developed and empirically tested among students in higher education in Malaysia. The findings obtained from this study can lead to new insights on Cloud e-learning acceptance in higher education.

\section{Theoretical Models to Explain IT Usage}

\subsection{Review of cloud e-learning frameworks}

Inspired by the emergence of Cloud Computing in e-learning, many educational researchers have started to devise and develop e-learning frameworks embracing Cloud Computing. A few existing Cloud e-learning frameworks were reviewed in terms of the strengths, weaknesses, and values added into the present research.

Shukur et al. proposed a Cloud Computing framework named CCF_HEI_DC for HEIs in developing countries [10]. Adopting Cloud Computing in this framework aims to achieve the educational goals with reduced investment cost for required IT infrastructure. On top of the incorporation of the widely recognised Cloud services (SaaS, PaaS and IaaS), a new Cloud service, DaaS (Data as a Service) was introduced in CCF_HEI_DC as a revolutionary new feature to provide raw data and generated data effectively. DaaS enables reading and writing of data through remote database access, allowing a wider range of access for external data sources [10]. This feature is beneficial to higher education, especially for developing countries which suffer from a lot of challenges to acquire or share information. In addition, CCF_HEI_DC is designed in a way that it could be used as a base framework suited for any developing countries. With this notation, CCF_HEI_DC along with its revolutionary DaaS feature 
was adopted into present research as added-value, considering Malaysia is also one of the developing countries.

Johnson et al. proposed a three-layer framework called E-Learning Education Cloud with some efficiency and personalisation features to enhance e-learning services [11]. All the three layers cover the front end for user access and the back end for Cloud processing. A notable feature in this framework is the real-time collaboration and communication as well as effective content delivery. The Cloud is utilised to flexibly scale the size of high-capacity video files and adapt its stream rate according to users' device capacity. Besides that, user profile feature introduced in this framework is great for personalisation purposes, such as keeping track of personal learning progress, storing personalised learning content, etc. [11]. These constructive features were adopted into the present research for enhanced learning experiences.

Kaur and Chawla proposed Cloud-based E-Learning (CEL) to provide a platform for the advanced Java e-learning implementation in the Cloud [12]. One of the worthmentioning modules in CEL is the well-defined learning content such as content creation, content delivery, assessment, etc. in the Learning Application layer. CEL utilises Web 2.0 tools to develop Cloud e-learning applications which allow effective content creation and delivery, highly accessible learning content, ease of assessment and performance progress monitoring [12]. Nevertheless, CEL might be overcustomised for Java programming, for instance, the content creation tools may not be suitable to create learning content for other courses. Thus, the definitions of Cloud learning content were adopted into the present research with further envision. Appropriate Web 2.0 tools and Cloud tools have been explored and considered for the development Cloud learning content in present study.

\subsection{Review of prominent theories and models for technology acceptance}

Prominent models and theories relating to understanding user perceptions of information technology (IT) and user acceptance of IS have been widely studied in technology acceptance field. For the sake of having a better understanding on how user behaviour is associated with IS acceptance, it is crucial to be inspired by what have been learned from previous researches about user behaviour and their interactions with technology.

Technology Acceptance Model (TAM): A vast literature has proven the significance of perceived usefulness and perceived ease of use in TAM [13] as major determinants for technology acceptance [14][15][16][17]. However, apart from perceived usefulness and perceived ease of use, TAM does not consider factors such as enjoyment, computer self-efficacy, social influence, etc. as a determinant of behavioural intention. Since technology evolution and user perception change over time, TAM is no longer sufficient to explain technology acceptance. Therefore, in this study, constructs in TAM along with significant factors from other models will be integrated to produce a more comprehensive technology acceptance framework.

Unified Theory of Acceptance and Use of Technology (UTAUT): UTAUT [18] has been adopted to analyse its capability to predict adoption in various field of research, for instance, Internet banking [19], mobile learning [20], e-learning [21], and 
biometric [22]. Nevertheless, the effects of system design and data quality criteria were not addressed. Thus, investigation of user acceptance for educational technology is not complete with this model alone. This research gap will be filled in the proposed integrated framework.

Information System (IS) success model: The two key factors in IS Success Model [23] have been analysed in several studies and proven to be generally significant [24][25]. With these notations, system quality will be integrated into the proposed framework in this study. Information quality, however, will be further explored in the aspect of learning object criteria.

Motivational Model (MM): Motivation theory consists of two major factors of motivations: extrinsic motivation and intrinsic motivation [26]. It is proven that people will be willing to spend more effort and time on a task and have greater IT acceptance when it creates a high level of enjoyment. In view that enjoyment plays an obviously important role as intrinsic motivation on user behavioural intention, it will thus be included in the integrated framework.

Social Cognitive Theory (SCT): A key principle of SCT [27] is the concept of self-efficacy. Computer self-efficacy, referring to "an individual's confidence in his or her capability to use new technology", is an important predictor for technology acceptance [28][29]. Computer self-efficacy has been proven for its encouraging effect on technology acceptance for learning purposes [30][31][32][33]. With these notations, computer self-efficacy will be adopted into the integrated framework to examine its significance towards intention to use Cloud e-learning.

Expectancy Value Model (EVM): EVM was initiated by Eccles et al. [34] to investigate mathematics achievement domain. It was later being refined on the constructs of expectancies and subjective task values [35]. Subjective task value is subdivided into four components: attainment value, utility value, intrinsic value, and relative cost [35]. Expectancy value theory were redefined in a study to analyse the experience of underrepresented students of colour in educational settings, and the study concluded expectancy value theory is dynamic and can be applied to student behaviour across numerous circumstances [36]. Since EVM is originally proposed for mathematics domain, not all the constructs are suited for Cloud e-learning which is different in its learning nature, pedagogically and technologically. Therefore, only relevant constructs namely Attainment Value and Utility Value are adopted into the proposed framework to examine Cloud e-learning acceptance.

Modelling learning objects criteria: Three broad criteria are used to assess the learning materials, namely Quality of Content, Potential Effectiveness, and Ease of Use [37]. Digital Library Network for Engineering and Technology (DLNET) added a review criterion called Pedagogical Effectiveness to build up and maintain the quality, integrity, and pedagogical value of learning objects in its repository [38]. Since then, studies have been conducted to evaluate learning objects for different education sectors. Haughey and Muirhead [39] developed an evaluation instrument to assess learning objects for K-12 education sector, and found it useful in identifying important characteristics such as accessibility criterion, pedagogical issues, etc. In 2008, a study was conducted to examine technical quality, content quality, and pedagogical quality as key factors towards intention to adopt learning objects [9]. The finding showed that 
pedagogical quality had significant a positive relationship on perceived usefulness, which also had a significant positive on adoption intention to use learning objects. With these notations, content quality and pedagogical quality will be adopted into the integrated framework to examine the impact of Cloud e-learning objects criteria towards its acceptance. Technical quality, however, will not be adopted because it is akin to system quality construct in IS success model. System quality construct is selected in this study because it is more suited to explain the system characteristics of Cloud e-learning.

\section{$3 \quad$ Research Framework}

The theories and models discussed in the literature review section have adopted a few constructs which can serve as a framework to evaluate Cloud e-learning acceptance among students in higher education. Figure 1 describes the proposed integrated technology acceptance framework. The independent variables namely System Quality, Content Quality, Pedagogical Quality, Perceived Usefulness, Perceived Ease of Use, Social Influence, Facilitating Conditions, Attainment Value, Utility Value, Computer Self Efficacy, and Enjoyment serve as predictors of Cloud e-learning. The dependent variable in this framework is the intention to use Cloud e-learning, which is measured by the set of independent variables.

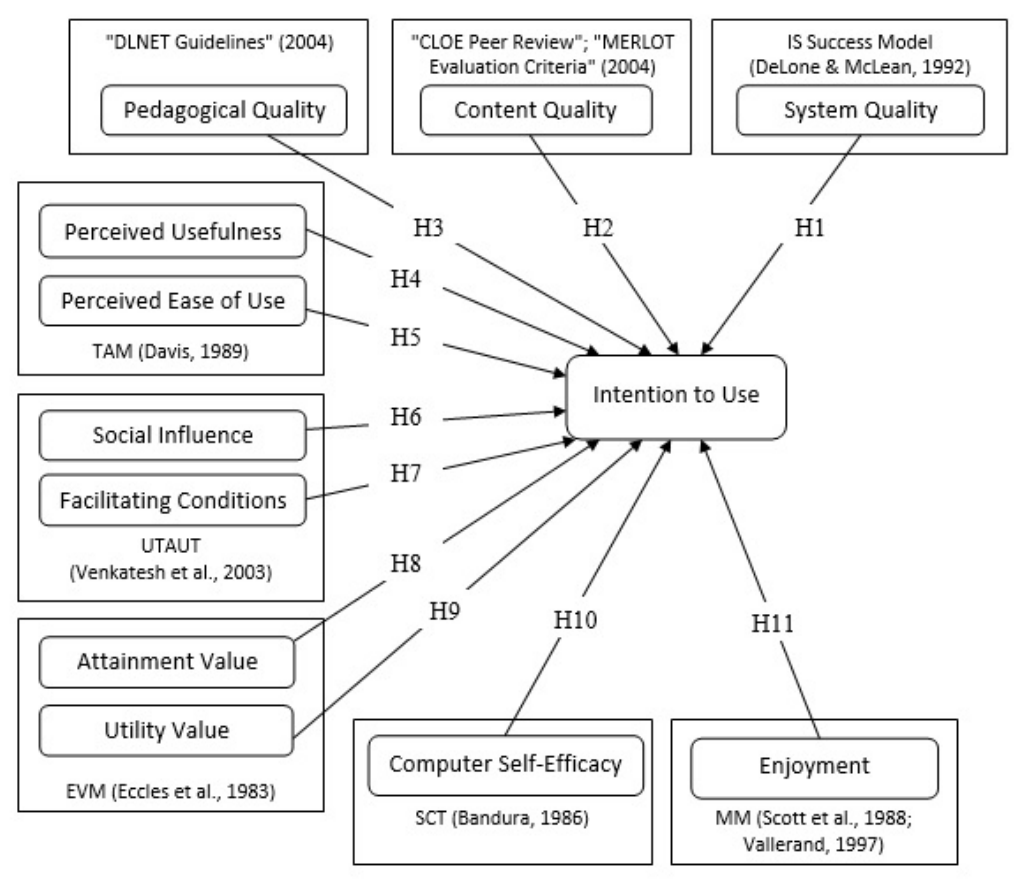

Fig. 1. Integrated Technology Acceptance Framework 
The proposed framework was conceptualised based on the integration TAM [13], UTAUT [18], IS Success Model [23], Learning Object Criteria [37][38], EVM [34], SCT [27], and MM [26][40]. Table 1 exhibits the summary of constructs for the proposed framework.

Table 1. Summary of Constructs

\begin{tabular}{|l|l|c|}
\hline \multicolumn{1}{|c|}{ Construct } & \multicolumn{1}{|c|}{ Definition } & Source \\
\hline $\begin{array}{l}\text { System Quality } \\
\text { (SQ) }\end{array}$ & $\begin{array}{l}\text { Measure the desired characteristics of Cloud e-learning, e.g., system reliability, } \\
\text { availability, flexibility, functionality). }\end{array}$ & {$[23]$} \\
\hline $\begin{array}{l}\text { Content Quality } \\
\text { (CQ) }\end{array}$ & $\begin{array}{l}\text { Measure the structure, depth, relevance, reusability, shareability of Cloud e- } \\
\text { learning content. }\end{array}$ & {$[37]$} \\
\hline $\begin{array}{l}\text { Pedagogical } \\
\text { Quality (PQ) }\end{array}$ & $\begin{array}{l}\text { Measure the potential effectiveness of Cloud e-learning content to meet learning } \\
\text { goals. }\end{array}$ & {$[38]$} \\
\hline $\begin{array}{l}\text { Perceived Use- } \\
\text { fulness (PU) }\end{array}$ & $\begin{array}{l}\text { The degree to which an individual believes that using Cloud e-learning would } \\
\text { improve his or her learning productivity. }\end{array}$ & {$[13]$} \\
\hline $\begin{array}{l}\text { Perceived Ease } \\
\text { of Use (PEU) }\end{array}$ & $\begin{array}{l}\text { The degree to which an individual believes that using Cloud e-learning would be } \\
\text { free of cognitive effort. }\end{array}$ & {$[13]$} \\
\hline $\begin{array}{l}\text { Social Influence } \\
\text { (SI) }\end{array}$ & $\begin{array}{l}\text { The extent to which an individual believes that important others believe that he } \\
\text { or she should use the technology. }\end{array}$ & {$[18]$} \\
\hline $\begin{array}{l}\text { Facilitating } \\
\text { Conditions (CF) }\end{array}$ & $\begin{array}{l}\text { The degree to which an individual believes that an organizational and technical } \\
\text { infrastructure exist to support the use of Cloud e-learning. }\end{array}$ & {$[18]$} \\
\hline $\begin{array}{l}\text { Attainment } \\
\text { Value (AV) }\end{array}$ & The importance of doing well on a task & {$[34]$} \\
\hline $\begin{array}{l}\text { Utility Value } \\
\text { (UV) }\end{array}$ & How well a task fulfils current or future goals & {$[34]$} \\
\hline $\begin{array}{l}\text { Computer Self- } \\
\text { Efficacy (CSE) }\end{array}$ & An individual's confidence in his or her capability to use Cloud e-learning. & {$[27]$} \\
\hline Enjoyment (E) & The degree to which an individual experience joy when using Cloud e-learning. \\
\hline $\begin{array}{l}\text { Intention to Use } \\
\text { (IU) }\end{array}$ & $\begin{array}{l}\text { The likelihood that an individual will use Cloud e-learning to improve learning } \\
\text { productivity. }\end{array}$ & {$[13]$} \\
\hline
\end{tabular}

The following hypothesis was then derived.

H1: SQ is positively associated with intention to use Cloud e-learning.

$\mathrm{H} 2$ : CQ is positively associated with intention to use Cloud e-learning.

$\mathrm{H} 3$ : PQ is positively associated with intention to use Cloud e-learning.

H4: PU is positively associated with intention to use Cloud e-learning.

H5: PEU is positively associated with intention to use Cloud e-learning.

H6: SI is positively associated with intention to use Cloud e-learning.

H7: FC is positively associated with intention to use Cloud e-learning.

H8: AV is positively associated with intention to use Cloud e-learning.

H9: UV is positively associated with intention to use Cloud e-learning.

H10: CSE is positively associated with intention to use Cloud e-learning.

H11: E is positively associated with intention to use Cloud e-learning. 


\section{$4 \quad$ Research Methodology}

\subsection{Cloud e-learning module development}

A comprehensive e-learning module is designed and developed utilizing a series of Web 2.0 and Cloud learning tools. G Suite is the main approach in our Cloud-based learning module development. G Suite is a Cloud computing comprising core suite of productivity and collaboration applications offered free of charge by Google to education landscapes. In the Cloud-based learning module, Google Classroom serves as the platform to provide a flexible and personalized learning. Students will be able to personalize their own learning process according to their own pace and speed of mastering the learning content. Incorporated into Google classroom is the Blendspace, where all the learning content are compiled and shared to students. Multiple modes of learning through the varieties of Cloud-based learning objects are provided in multiple formats and modalities, for example, still infographics, animated diagrams, short videos, interactive web, etc. Figure 2 presents a complete chapter in Cloud e-learning module.

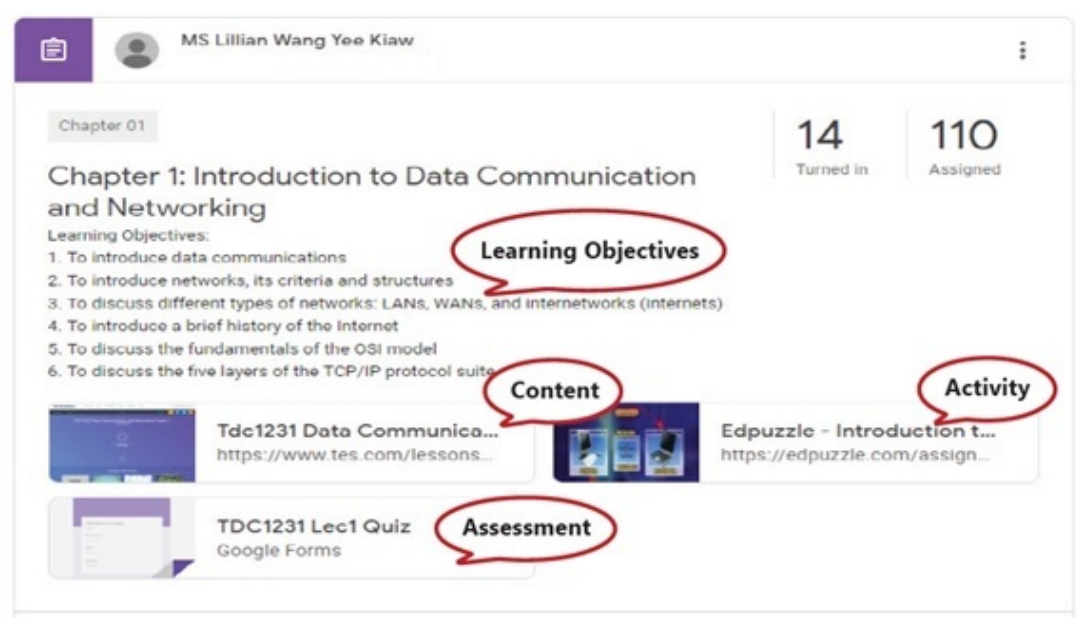

Fig. 2. Figure 1: Cloud E-Learning Module

In order to gain a deeper understanding of this study, the developed Cloud elearning module is introduced to a group of selected university students. The students were given one month to try out Cloud e-learning module to gain firsthand experience on Cloud e-learning. Subsequently, students will participate in a survey to study their intention to use Cloud e-learning. 


\subsection{Sampling}

In this study, convenience sampling was selected. A survey was conducted at a private university in southern region of Malaysia. Quantitative research requires adequate sample for empirical study [41]. Thus, a group of 222 students taking IT courses in the university, regardless of gender, age, year of study and IT major participated in the survey voluntarily. Data collection ended when the total responses achieved an adequate sample size obligatory for statistical analysis.

\subsection{Measurement instrument design and development}

A set of 72-question Likert-scale questionnaire was formulated. The English written questionnaire was set for self-perceived characteristics; therefore, the questions were phrased to be of self-understanding of the respondents. Since Cloud e-learning was designed for IT students, the questions were also expressed in the context of IT relevance. The 5-scale Likert style questions were labelled from "Strongly Disagree", "Disagree", "Neutral", "Agree" and "Strongly Agree", scaled from 1 to 5 respectively.

All the items used to measure the constructs were adapted from prior validated studies with some modifications to fit specific context of Cloud e-learning. To establish content validity of the constructs, the questionnaire was first subjected to an expert review by a researcher in the related field. Subsequently, a pilot test which is considered as a prerequisite to validate the survey measurements was conducted on a small group of selected students to ensure further redefine the construct measurement domain. Feedbacks of the pilot test were gathered via face-to-face interview. The interview has guaranteed that the survey items are suitable for the scope of study. After the interview, the questionnaire was finally refined and administered to the full sample.

\subsection{Research design and procedures}

Survey is one of the most widely used research method in technology acceptance study. It offers high representativeness of the entire population and it is low cost. Therefore, quantitative survey is adopted in this study to investigate the students' intention to use Cloud e-learning module.

\subsection{Statistical analysis techniques}

To test the proposed hypotheses, structural equation modelling (SEM) was used. SEM is considered as the second-generation multivariate data analysis method that gains popularity among social scientist because of its ability in testing theoretical supported and additive causal models [42][43][44].

In this study, two stage-analyses were adopted. The first stage uses confirmatory factor analysis (CFA) to estimate the parameters by verifying the internal consistency, 
reliability, and validity of the measurement model. Then, structural model was estimated, and the proposed hypotheses were confirmed.

\section{$5 \quad$ Data Analysis and Results}

\subsection{Demographic analysis}

A total of 222 respondents participated in the study by completing a questionnaire. Table 2 shows the demographic details and e-learning experience of the respondents.

Table 2. Demographic profile and e-learning experience of respondents

\begin{tabular}{|l|l|c|c|}
\hline & & Count & Percentage \\
\hline Gender & Male & 157 & 70.72 \\
\hline & Female & 65 & 29.28 \\
\hline & 18 and below & 1 & 0.45 \\
\hline & 19 & 17 & 7.66 \\
\hline & 20 & 74 & 33.33 \\
\hline & 21 & 51 & 22.97 \\
\hline & 22 & 34 & 15.32 \\
\hline Year of Study & 23 and above & 45 & 20.27 \\
\hline & 1 st Year & 120 & 54.05 \\
\hline & 2nd Year & 74 & 33.33 \\
\hline & 3rd Year & 26 & 11.71 \\
\hline IT Major & 4th Year & 2 & 0.90 \\
\hline & Artificial Intelligence & 69 & 31.08 \\
\hline & Bioinformatics & 9 & 4.05 \\
\hline & Data Communications & 32 & 14.41 \\
\hline & IT Management & 26 & 11.71 \\
\hline & Security Technology & 86 & 38.74 \\
\hline & Yes & 220 & 99.10 \\
\hline & No & 2 & 0.90 \\
\hline
\end{tabular}

\subsection{Confirmatory factor analysis}

Three main assessment criteria were adopted to assess the constructs: internal consistency reliability, convergent validity and discriminant validity. From Table 3 , it is observed that all the constructs have met the satisfactory level of CR result of $\geq 0.7$, which were considered acceptable [45]. It is thus concluded that the constructs met reliability validity requirement at this stage.

To assess convergent validity, the outer loadings of the indicators and the average variance extracted (AVE) were measured [45]. Table 3 shows that all construct indicators were having the outer loading $\geq 0.6$, which were considered to be acceptable [41]. In sum, all indicators attained the threshold value; hence, satisfactory indicator reliability was achieved [45]. 
Table 3. Composite Reliability and Convergent Validity

\begin{tabular}{|c|c|c|c|c|}
\hline Construct & Item & Loading & $\mathbf{C R}$ & AVE \\
\hline \multirow{6}{*}{ System Quality (SQ) } & SQ1 & 0.633 & 0.873 & 0.535 \\
\hline & SQ2 & 0.814 & & \\
\hline & SQ3 & 0.748 & & \\
\hline & SQ4 & 0.728 & & \\
\hline & SQ5 & 0.664 & & \\
\hline & SQ6 & 0.786 & & \\
\hline \multirow{5}{*}{ Content Quality (CQ) } & CQ1 & 0.717 & 0.841 & 0.515 \\
\hline & CQ2 & 0.702 & & \\
\hline & CQ3 & 0.630 & & \\
\hline & CQ5 & 0.761 & & \\
\hline & CQ6 & 0.769 & & \\
\hline \multirow{5}{*}{ Pedagogical Quality (PQ) } & PQ1 & 0.702 & 0.842 & 0.516 \\
\hline & PQ2 & 0.701 & & \\
\hline & PQ3 & 0.798 & & \\
\hline & PQ4 & 0.733 & & \\
\hline & $\mathrm{PQ5}$ & 0.651 & & \\
\hline \multirow{6}{*}{ Perceived Usefulness (PU) } & PU1 & 0.741 & 0.905 & 0.614 \\
\hline & PU2 & 0.799 & & \\
\hline & PU3 & 0.819 & & \\
\hline & PU4 & 0.819 & & \\
\hline & PU5 & 0.733 & & \\
\hline & PU6 & 0.786 & & \\
\hline \multirow{6}{*}{ Perceived Ease of Use (PEU) } & PEU1 & 0.716 & 0.894 & 0.584 \\
\hline & PEU2 & 0.777 & & \\
\hline & PEU3 & 0.763 & & \\
\hline & PEU4 & 0.788 & & \\
\hline & PEU5 & 0.747 & & \\
\hline & PEU6 & 0.792 & & \\
\hline \multirow{5}{*}{ Social Influence (SI) } & SI1 & 0.758 & 0.856 & 0.544 \\
\hline & SI2 & 0.775 & & \\
\hline & SI3 & 0.715 & & \\
\hline & SI4 & 0.716 & & \\
\hline & SI5 & 0.722 & & \\
\hline \multirow{5}{*}{ Facilitating Conditions (FC) } & FC1 & 0.675 & 0.852 & 0.535 \\
\hline & FC2 & 0.740 & & \\
\hline & FC3 & 0.709 & & \\
\hline & FC5 & 0.785 & & \\
\hline & FC6 & 0.745 & & \\
\hline \multirow{6}{*}{ Attainment Value (AV) } & AV1 & 0.737 & 0.893 & 0.583 \\
\hline & AV2 & 0.757 & & \\
\hline & AV3 & 0.772 & & \\
\hline & AV4 & 0.809 & & \\
\hline & AV5 & 0.741 & & \\
\hline & AV6 & 0.763 & & \\
\hline \multirow{2}{*}{ Utility Value (UV) } & UV1 & 0.816 & 0.889 & 0.573 \\
\hline & UV2 & 0.709 & & \\
\hline
\end{tabular}




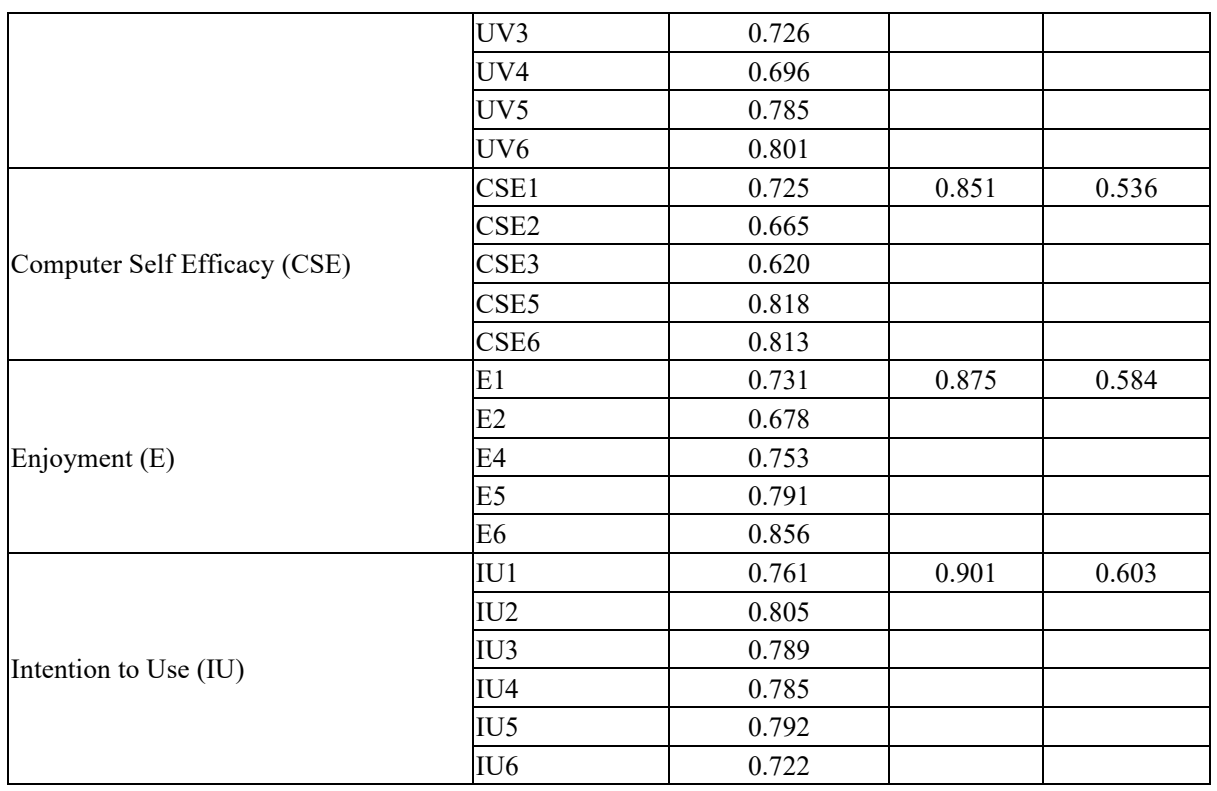

Note: CQ4, PQ6, SI6, FC4, CSE4, and E3 were deleted due to low loadings.

Discriminant validity was subsequently assessed to determine the extent to which the factors are truly distinct from other factors in the model [44]. To assess discriminant validity, Heterotrait-Monotrait ratio of correlations (HTMT) were examined.

Henseler, Ringle, and Sarstedt [46] suggested HTMT as "an alternative approach to assess discriminant validity to measure the ratio of correlations within the constructs to correlations between the constructs". HTMT was used to ensure every construct in this study is truly different from one another. From Figure 3 below, it can be observed that most of the HTMT values were not greater than HTMT.85 value of 0.85 , and none of the HTMT values were greater than HTMT.90 value of 0.90 , indicating the sufficiency of discriminant validity [46]. HTMT thus confirmed the discriminant validity of the constructs. In other words, there was no issue of high cross-loading among one another.

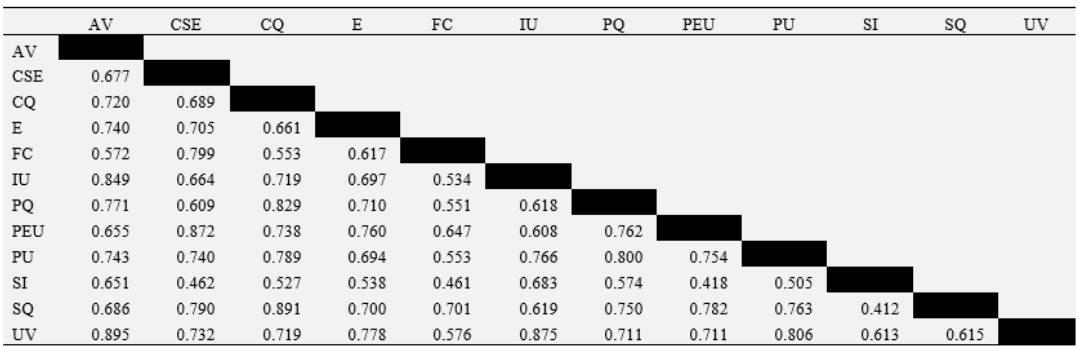

Fig. 3. Discriminant Validity - HTMT 
In sum, the results of the confirmatory factor analysis indicated that the best fitting measurement model was accepted. Thus, the confirmed measurement model was incorporated into the analysis of SEM with latent variables.

\subsection{Structural model assessment}

Path analysis was then performed to evaluate the hypothesized causal relationships that predict the intention to use Cloud e-learning. Table 5 presents the assessment of the structural model. Prior to the structural analysis, it is crucial to address the lateral collinearity issue. To assess collinearity, variance inflation factor (VIF) values were considered and checked. Result shows that the lateral multicollinearity was clearly above the threshold of 0.2 and below the threshold of 5, indicating lateral multicollinearity was not a concern in this structural model [45]. Eleven direct hypotheses were devised in this study. Estimates (path coefficients and t-values) for the structural model were obtained to test the hypothesized relationships among constructs. Table 4 presents the collinearity assessment and results of the hypothesis test.

Table 4. Collinearity Assessment and Results of Hypothesis Test

\begin{tabular}{|l|l|c|c|c|c|c|}
\hline \multicolumn{2}{|c|}{ Hypothesis } & VIF & Std Beta & Std Error & t-value & p-value \\
\hline H1 & SQ -> IU & 3.112 & 0.005 & 0.073 & 0.068 & 0.473 \\
\hline H2 & CQ -> IU* & 2.646 & 0.134 & 0.072 & 1.868 & 0.031 \\
\hline H3 & PQ -> IU** & 2.402 & 0.159 & 0.055 & 2.907 & 0.002 \\
\hline H4 & PU -> IU** & 2.895 & 0.192 & 0.073 & 2.623 & 0.004 \\
\hline H5 & PEU -> IU & 3.040 & -0.030 & 0.082 & 0.367 & 0.357 \\
\hline H6 & SI -> IU** & 1.573 & 0.180 & 0.057 & 3.137 & 0.001 \\
\hline H7 & FC -> IU & 1.814 & 0.018 & 0.057 & 0.324 & 0.373 \\
\hline H8 & AV -> IU*** & 3.159 & 0.256 & 0.072 & 3.543 & 0.000 \\
\hline H9 & UV -> IU*** & 3.484 & 0.304 & 0.082 & 3.700 & 0.000 \\
\hline H10 & CSE -> IU & 2.930 & 0.022 & 0.076 & 0.288 & 0.387 \\
\hline H11 & E -> IU & 2.430 & 0.054 & 0.068 & 0.791 & 0.215 \\
\hline
\end{tabular}

Note: $* * * \mathrm{p}<0.001, * * \mathrm{p}<0.01, * \mathrm{p}<0.05$

Results from the structural model assessment revealed that six out of eleven exogenous constructs namely CQ, PQ, PU, SI, AV and UV have $t$-value $>1.645$ for significance level of 5 percent $(\alpha=0.05)$ in one-tailed test, indicating significantly positive relationships with UI [45].

Figure 4 presents the results from CFA and the structural model assessment. To evaluate the predictive accuracy of endogenous construct of the structural model, coefficient of determination, $\mathrm{R}^{2}$ value, was examined. The $\mathrm{R}^{2}$ of $\mathrm{UI}$ construct is 0.694 , indicating that the exogenous constructs substantially explain $69.4 \%$ of the variance in UI, which evaluates to substantial predictive power [42][47]. Referring to stricter threshold evaluations, $\mathrm{R}^{2}$ value of 0.694 also evaluates to moderate predictive power [45][48]. 


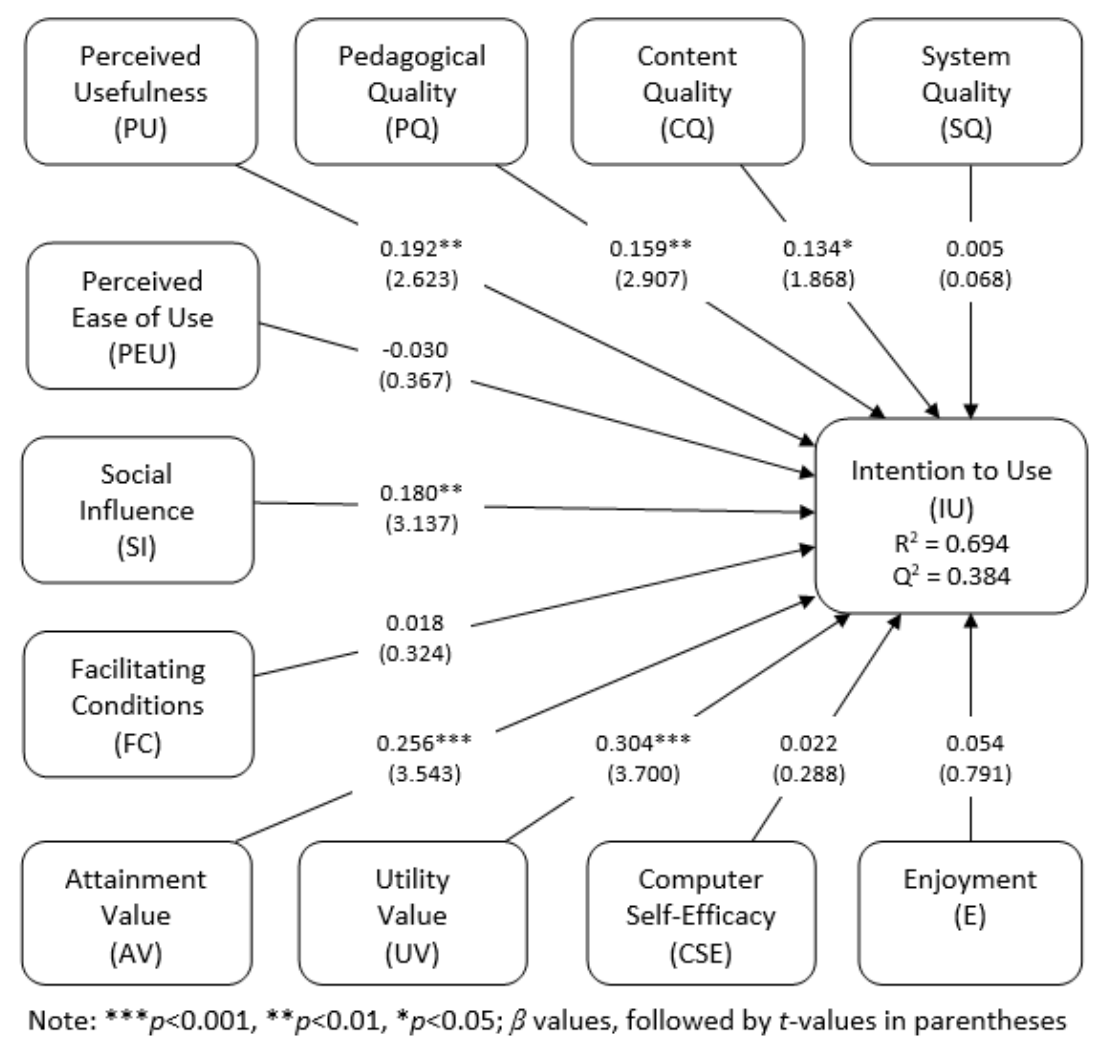

Fig. 4. Measurement and Structural Model Assessment Results

\section{Discussions and Specific Implications for Each Hypothesis}

Possessing R2 value of 0.694 which indicated substantial predictive power [42][47] implies that the integrated framework strongly predicted intention to use Cloud elearning. Besides that, the integrated framework also possessed Q2 value of 0.384 which implies medium predictive relevance for intention to use Cloud e-learning [45][49][50]. Overall, the findings revealed that CQ, PQ, PU, SI, AV and UV appeared to be strong predictors of UI, while SQ, PEU, FC, CSE and E were found insignificant. Table 6 presents summary of hypothesis results.

The hypothesis results found that the content and pedagogical quality of learning objects significantly influence intention to use Cloud e-learning. This implies that it is crucial to carefully attend to the characteristics of Cloud e-learning objects during the design and development phases [51]. Cloud e-learning content should be well organized, structured, and easy to understand. The Cloud characteristics of reusable, scalable and shareable should be made available in Cloud e-learning [52]. Besides that, educators and instructional designers should also carefully consider the needs and values of Cloud e-learning objects to ensure higher engagement in Cloud e-learning. 
Table 5. Summary of Hypothesis Results

\begin{tabular}{|l|l|l|}
\hline \multicolumn{2}{|c|}{ Hypothesis } & \multicolumn{1}{|c|}{ Decision } \\
\hline H1 & System quality is positively associated with intention to use Cloud e-learning. & Not supported \\
\hline H2 & Content quality is positively associated with intention to use Cloud e-learning. & Supported \\
\hline H3 & Pedagogical quality is positively associated with intention to use Cloud e-learning. & Supported \\
\hline H4 & Perceived usefulness is positively associated with intention to use Cloud e-learning. & Supported \\
\hline H5 & Perceived ease of use is positively associated with intention to use Cloud e-learning. & Not supported \\
\hline H6 & Social influence is positively associated with intention to use Cloud e-learning. & Supported \\
\hline H7 & Facilitating conditions is positively associated with intention to use Cloud e-learning. & Not supported \\
\hline H8 & Attainment value is positively associated with intention to use Cloud e-learning. & Supported \\
\hline H9 & Utility value is positively associated with intention to use Cloud e-learning. & Supported \\
\hline H10 & $\begin{array}{l}\text { Computer self-efficacy is positively associated with intention to use Cloud e- } \\
\text { learning. }\end{array}$ & Not supported \\
\hline H11 & Enjoyment is positively associated with intention to use Cloud e-learning. & Not supported \\
\hline
\end{tabular}

Decent learning strategies such as objectives, introduction and summary help students to understand the learning content better. Good learning content such as activities, assessments, and different content formats with appropriate pedagogical features highly support in achieving learning goals. In line with other studies [51][53][54], this study has thus validated content quality and pedagogical quality of learning objects as significant key factors towards intention to use Cloud e-learning.

System quality, on the other hand, exhibited contradictory results, as it was found to be insignificant in the integrated framework. This contradicted studies that proved the importance of system quality as a key determinant of technology acceptance [55][56]. One possible explanation that may account for this finding is because both Cloud computing and e-learning are already well established and high stability where system quality is not a major concern in the context of this study. Hence, system quality has relatively low influences towards intention to use Cloud e-learning.

The results also suggested that perceived usefulness has significant influence towards intention to use Cloud e-learning. This implies that it is essential to ensure Cloud e-learning is able to enhance learning effectiveness and performance, as well as to increase learning productivity. This finding is consistent with prior literatures [14][15] [16][17], and thus confirmed perceived usefulness as a significant key factor towards intention to use Cloud e-learning. However, perceived ease of use was found to be insignificant in the integrated framework, contrary to the findings in previous literatures [14][15] [16][17]. This may imply a change in thinking paradigm among younger generations who are mostly savvy with digital technologies where perceived ease of use is no longer crucial in determining intention to use [32][56]. Similar findings also revealed that perceived ease of use was a weak predictor for students' behavioural intentions to use YouTube for procedural learning [57], and students' adoption intention of mobile technology for aiding student-lecturer interactions [32][56].

Social influence plays an important supporting role in technology usage intention, and this is proven by the results this study. This implies that students are more likely to use Cloud e-learning when their peers, teachers, or someone important to them suggest them to use it. This is in line with prior related studies [20][21], and thus, social influence as a significant key factor towards intention to use Cloud e-learning is 
confirmed. Facilitating conditions, on the other hand, portrayed contradictory findings, as it was found to be insignificant. This contradicted studies that proved facilitating conditions to be a key predictor in technology acceptance [20][21]. Nevertheless, Venkatesh et al. [18] indicated that facilitating conditions are not significant in predicting intention; it has a straightforward relationship on usage behaviour instead.

The results further suggested that attainment value and utility value are strong predictors towards intention to use Cloud e-learning, which is consistent with other studies that claimed likewise [36][58][59][60]. This implies that students are willing to use Cloud e-learning if it is able to give them sense of achievement, sense of confidence, sense of independence, and further confirm their learning competency. Besides that, the willingness to use Cloud e-learning increases when Cloud e-learning helps them perform better in examinations, shorten their exam preparation time, and important for their future endeavour.

Computer self-efficacy was found to be insignificant, which contradicted studies that proved computer self-efficacy as a crucial determinant of technology acceptance [30][31][32][33]. One possible explanation that may account for this finding is that, younger generations are very well adapted with digital devices and technologies in their everyday life. In addition, since the respondents were IT students and highly computer literate, thus the confidence issue in their ability to use technology is no longer relevant when it comes to predict intention to use Cloud e-learning. A similar recent finding also revealed that computer self-efficacy is no longer relevant for adoption intentions of mobile technology in learning [56].

Lastly, the hypothesis results showed that enjoyment does not significantly influence intention to use Cloud e-learning, contradicted studies that proved enjoyment being one of the key factors in predicting technology acceptance [56][61][62]. The insignificance of this construct could indicate that although enjoyment would drive students to use technology because they enjoy using it, but when it becomes a part of learning process, the factor becomes less significant. Gefen and Straub [63] proclaimed that extrinsic factors such as perceived usefulness and perceived ease of use have higher impact on technology acceptance than intrinsic factors such as enjoyment and computer self-efficacy. Besides that, due to the unanticipated, unorganised and unacknowledged nature of learning via technology, most students perceived that digital technology is mainly for leisure purposes and not for learning purposes [64].

\section{Conclusion, Limitation and Implication of Study}

In sum, this study presented a comprehensive framework which integrated eleven factors captured from seven sources of IS success, learning object criteria, technology acceptance, motivations, social cognitive, and expectancy values. The integrated framework explained intention to use Cloud e-learning from a more complete set of perspectives. It is timely because technological progress has resulted in constant change of social structures and continuous evolution of attitudes and values. In addition, the integrated framework is unique in a way that only constructs that matched 
the study objectives were selected and specifically tested for its significance towards intention to use Cloud e-learning.

The main implication of this study is the importance of learning object's content and pedagogical quality in Cloud e-learning. A good learning content encourages high acceptance in Cloud e-learning. System quality, on the other hand, differs from prior related studies, reflects that reliability, convenience, interactivity and navigation, flexibility, accessibility, and system feature of current Cloud technology and elearning application is good enough and it is not a major concern in this study. Besides that, perceived usefulness has once again proved to be a stronger influence than perceived ease of use on intention to use. For the IT students who were experienced technology user, perceived ease of use is not an important factor of system usage intention; perceived usefulness is more crucial instead [13]. The decision whether to use Cloud e-learning is also very much associated to social influence, attainment value, and utility value. Insignificance of factors such as facilitating conditions, computer self-efficacy, and enjoyment shows that young savvy technology users do not have to exert cognitive efforts to reflect their confidence in using Cloud e-learning.

There is a limitation in this study where the scope of respondents was limited to IT students in one higher learning institution. IT students are generally more technology savvy if compared to non-IT students. Hypotheses test for perceived ease of use, facilitating conditions, and computer self-efficacy could have yielded different results if the respondents' range is widened. Thus, future work of interest is to expand this data collection to other study fields and even to other higher learning institutions in order to obtain a more generalized statistical result.

\section{$8 \quad$ References}

[1] Elgelany, A., \& Alghabban, W. G. (2017). Cloud Computing: Empirical Studies in Higher Education. International Journal of Advanced Computer Science and Applications, 8(10), 1-12. Retrieved from http://net.educause.edu/section_params/conf/CCW10/highered.pdf

[2] Alharthi, A., Madini, O. A., Robert, J. W., \& Gary, B. W. (2017). An exploratory study for investigating the critical success factors for cloud migration in the Saudi Arabian higher education context. Telematics and Informatics, 34(2), 664-678. https://doi.org/10.1016/j.te le.2019.04.004

[3] Gamundani, A. M., Kanyangela, M., \& Chitauro, S. (2015). A Preliminary Assessment Of Cloud Computing E-learning Solutions In Namibia. Journal of Multidiscipline Engineering Science and Technology, 2(8), 1988-1993.

[4] Bosamia, M., \& Patel, A. (2016). An Overview of Cloud Computing for E-Learning with its Key Benefits. International Journal of Information Sciences and Techniques, 6(1/2), 110. https://doi.org/10.5121/ijist.2016.6201

[5] Ashtari, S., \& Eydgahi, A. (2017). Student perceptions of cloud applications effectiveness in higher education. Journal of Computational Science, 23, 173-180. https://doi.org/10.10 16/j.jocs.2016.12.007

[6] Divya, P., \& Prakasam, S. (2015). Effectiveness of Cloud based E-Learning System (ECBELS). International Journal of Computer Applications, 119(6), 29-36. https://doi.org/ $\underline{10.5120 / 21075-3750}$ 
[7] Rajput, L. S., \& Deora, B. S. (2017). Developing a Cloud Based E-Learning Framework for Higher Education Institutions (HEI). In International Conference on Innovation Research in Science, Technology and Management (pp. 237-244).

[8] Alajmi, Q., \& Sadiq, A. (2016). What should be done to achieve greater use of cloud computing by higher education institutions. 7th IEEE Annual Information Technology, Electronics and Mobile Communication Conference, IEEE IEMCON 2016, (October 2016), 15. https://doi.org/10.1109/IEMCON.2016.7746083

[9] Lau, S.-H. (2008). An Empirical Study of Students' acceptance of Learning Objects. Multimedia University, Melaka, Malaysia.

[10] Shukur, B. S., Khanapi, M., \& Ghani, A. (2018). A Cloud Computing Framework for Higher Education Institutes in Developing Countries (CCF _ HEI _ DC ) Problems of Higher Education Institutes in Developing. In International Conference on Intelligent and Interactive Computing IIC2018 (pp. 1-11). https://doi.org/10.1007/978-981-13-6031-2_24

[11] Johnson, S., Liu, X., Miao, H., Yuan, J., Jin, Y., Wei, Q., \& Xu, Z. (2016). A Framework of e-Learning Education Clouds to Efficiency and Personalization. Proceedings - 2016 3rd International Conference on Information Science and Control Engineering, ICISCE 2016. https://doi.org/10.1109/ICISCE.2016.17

[12] Kaur, G., \& Chawla, S. (2014). Cloud E Learning Application : Architecture and Framework. SSRG International Journal of Computer Science and Engineering (SSRG-IJCSE), 1(4), 1-5.

[13] Davis, F. D. (1989). Perceived Usefulness, Perceived Ease of Use, and User Acceptance of Information Technology. Mis Quarterly, 13(3), 319-340. https://doi.org/10.2307/249008

[14] Briz-Ponce, L., \& García-Peñalvo, F. (2015). An Empirical Assessment of a Technology Acceptance Model for Apps in Medical Education. Journal of Medical Systems, 39(11), 15. https://doi.org/10.1007/s10916-015-0352-x

[15] Hamid, A. A., Razak, F. Z. A., Bakar, A. A., \& Abdullah, W. S. W. (2016). The Effects of Perceived Usefulness and Perceived Ease of Use on Continuance Intention to Use EGovernment. Procedia Economics and Finance, 35(October 2015), 644-649. https://doi. org/10.1016/S2212-5671(16)00079-4

[16] Mou, J., Shin, D.-H., \& Cohen, J. (2017a). Tracing College Students' Acceptance of Online Health Services. International Journal of Human-Computer Interaction, 33(5), 371-384. https://doi.org/10.1080/10447318.2016.1244941

[17] Mou, J., Shin, D.-H., \& Cohen, J. (2017b). Understanding trust and perceived usefulness in the consumer acceptance of an e-service: a longitudinal investigation. Behaviour and Information Technology, 36(2), 125-139. https://doi.org/10.1080/0144929X.2016.1203024

[18] Venkatesh, Morris, Davis, \& Davis. (2003). User Acceptance of Information Technology: Toward a Unified View. MIS Quarterly, 27(3), 425. https://doi.org/10.2307/30036540

[19] Foon, Y. S., \& Fah, B. C. Y. (2011). Internet Banking Adoption in Kuala Lumpur: An Application of UTAUT Model. International Journal of Business and Management, 6(4). https ://doi.org/10.5539/ijbm.v6n4p161

[20] Thomas, T., Singh, L., \& Gaffar, K. (2013). The utility of the UTAUT model in explaining mobile learning adoption in higher education in Guyana. International Journal of Education and Development Useing Information and Communication Technology (IJEDICT), 9(3), 71-85. https://doi.org/10.5539/ass.v10n11p84

[21] Tan, P. J. B. (2013). Applying the UTAUT to understand factors affecting the use of english e-learning websites in Taiwan. SAGE Open, 3(4). https://doi.org/10.1177/2158244013 $\underline{503837}$ 
[22] Neo, H. F., Devinaga, R., Tong, D. Y. K., \& Teo, C. C. (2014). Biometric technology and privacy: a perspective from tourist satisfaction. J. of IT \& Tourism, 14(3), 219-237. https ://doi.org/10.1007/s40558-014-0014-8

[23] DeLone, W. H., \& McLean, E. R. (1992). Information systems success: The quest for the dependent variable. Information Systems Research, 3(1), 60-95. https://doi.org/10.1287/is $\underline{\text { re. } 3.1 .60}$

[24] Lederer, A. L., Maupin, D. J., Sena, M. P., \& Zhuang, Y. (2000). Technology acceptance model and the World Wide Web. Decision Support Systems, 29(3), 269-282. https://doi. org/10.1016/S0167-9236(00)00076-2

[25] Petter, S., DeLone, W. H., \& McLean, E. R. (2013). Information systems success: The quest for the independent variables. Journal of Management Information Systems, 29(4), 7-61. https://doi.org/10.2753/mis0742-1222290401

[26] Scott, W. ., Farh, J.-L., \& Podsakoff, P. M. (1988). The effects of "intrinsic" and "extrinsic" reinforcement contingencies on task behavior. Organizational Behavior and Human Decision Processes, 41(3), 405-425. https://doi.org/10.1016/0749-5978(88)90037-4

[27] Bandura, A. (1986). Social foundations of thought and action : a social cognitive theory. Englewood Cliffs, N.J. : Prentice-Hall, C1986. https://doi.org/10.5465/amr.1987.4306538

[28] Bandura, A. (1989). Regulation of Cognitive Processes Through Perceived Self-Efficacy. Developmental Psychology, 25(5), 729-735. https://doi.org/10.1037/0012-1649.25.5.729

[29] Compeau, D., \& Higgins, C. (1995). Computer self-efficacy: Development of a measure and initial test. Mis Quarterly, 19, 189-211. https://doi.org/10.2307/249688

[30] Alqurashi, E. (2016). Self-Efficacy in Online Learning Environments: A Literature Review. Contemporary Issues in Education Research (CIER), 9(1), 45. https://doi.org/10.190 30/cier.v9i1.9549

[31] Doménech-Betoret, F., Abellán-Roselló, L., \& Gómez-Artiga, A. (2017). Self-efficacy, satisfaction, and academic achievement: The mediator role of students' expectancy-value beliefs. Frontiers in Psychology, 8(JUL), 1-12. https://doi.org/10.3389/fpsyg.2017.01193

[32] Gan, C. L., \& Balakrishnan, V. (2017). Predicting acceptance of mobile technology for aiding student-lecturer interactions: An empirical study. Australasian Journal of Educational Technology, 33(2), 143-158. https://doi.org/10.14742/ajet.2525

[33] Valencia-Vallejo, N., López-Vargas, O., \& Sanabria-Rodríguez, L. (2016). Self-Efficacy in Computer-Based Learning Environments: A Bibliometric Analysis. Psychology, 07(14), 1839-1857. https://doi.org/10.4236/psych.2016.714170

[34] Eccles, J. S., Adler, T. F., Futterman, R., Goff, S. B., Kaczala, C. M., Meece, J. L., \& Midgley, C. (1983). Expectancies, Values, and Academic Behaviors. In J. T. Spence (Ed.), Achievement and Achievement Motivation. San Francisco, CA: W. H. Freeman.

[35] Wigfield, A., \& Eccles, J. S. (2000). Expectancy-value theory of achievement motivation. Contemporary Educational Psychology, 25(1), 68-81. https://doi.org/10.1006/ceps.1999. $\underline{1015}$

[36] Seals, C. (2016). Expectancy Value Theory: Racializing Values in Motivation Theory Using Racial Opportunity Cost Chris Seals Michigan State University. Urban Education Research and Policy Annual, 4(2), 56-70.

[37] "MERLOT Evaluation Criteria". (2004). Evaluation Criteria for Peer Reviews. Retrieved Nov 30, 2006, from http://taste.merlot.org/evaluationcriteria.html

[38] "DLNET Guidelines". (2004). DLNET Guidelines for the Reviewer. Retrieved May 28, 2005, from http://www.dlnet.vt.edu/ReviewerGuidelines.jsp\#review form

[39] Haughey, M., \& Muirhead, B. (2005). Evaluating Learning Objects for Schools. E-Journal of Instructional Science and Technology, 8(1). 
[40] Vallerand, R. J. (1997). Toward A Hierarchical Model of Intrinsic and Extrinsic Motivation. Advances in Experimental Social Psychology, 29, 271-360. https://doi.org/10.1016/S 0065-2601(08)60019-2

[41] Hair, J. F., Black, W. C., Babin, B. J., \& Anderson, R. E. (2010). Multivariate Data Analysis: A Global Perspective. (7, Ed.). Upper Saddle River, NJ: Pearson Education.

[42] Chin, W. W. (1998). Commentary: Issues and Opinion on Structural Equation Modeling. Mis Quarterly, 22(1). Retrieved from https://www.jstor.org/stable/249674

[43] Michael Haenlein, A. M. K. (2004). A beginner's guide to partial least squares analysis, Understanding Statistics”. Statistical Issues in Psychology and Social Sciences, Volume 3, 3(4), 283-297. https://doi.org/10.1207/s15328031us0304_4

[44] Ramayah, T., Cheah, J., Chuah, F., Ting, H., \& Memon, M. A. (2018). Partial Least Squares Structural Equation Modeling (PLS-SEM) using SmartPLS 3.0: An Updated Guide and Practical Guide to Statistical Analysis (2nd ed.). Pearson. Retrieved from https $: / /$ scholar.google.com/scholar?hl=en\&as $\mathrm{sdt}=0,5$ \&cluster $=6234200078132602017$

[45] Hair, J. F., Hult, T. M., Ringle, C. M., \& Sarstedt, M. (2017). A primer on partial least square structural equation modeling (PLS-SEM) (2nd ed.). Thousand Oaks, CA: SAGE Publications, Inc. https://doi.org/10.3926/oss.37

[46] Henseler, J., Ringle, C. M., \& Sarstedt, M. (2015). A new criterion for assessing discriminant validity in variance-based structural equation modeling. Journal of the Academy of Marketing Science, 43(1), 115-135. https://doi.org/10.1007/s11747-014-0403-8

[47] Cohen, J. (1988). Statistical Power Analysis for the Behavioral Science (2nd ed.). Hillsdale, NJ: Lawrence Erlbaum Associates. https://doi.org/10.1016/B978-0-12-179060$8.50012-8$

[48] Henseler, J. (2010). On the convergence of the partial least squares path modeling algorithm. Computational Statistics, 25(1), 107-120. https://doi.org/10.1007/s00180-009-0164$\underline{\mathrm{x}}$

[49] Seymour Geisser. (1975). A Predictive Approach to the Random Effect Model. Biometrika, 61(1), 101-107. https://doi.org/10.1093/biomet/61.1.101

[50] Stone, M. (1974). Cross-Validation and Multinomial Prediction. Biometrika, 61(3), 509515. https://doi.org/10.1093/biomet/61.3.509

[51] Lau, S., \& Woods, P. C. (2008). An investigation of user perceptions and attitudes towards learning objects. British Journal of Educational Technology, 39(4), 685-699. https://doi. org/10.1111/j.1467-8535.2007.00770.x

[52] Gong, C., Liu, J., Zhang, Q., Chen, H., \& Gong, Z. (2010). The characteristics of cloud computing. Proceedings of the International Conference on Parallel Processing Workshops, 275-279. https://doi.org/10.1109/ICPPW.2010.45

[53] Barhoumi Chokri. (2012). Factors Influencing The Adoption Of The E- Learning Technology In Teaching And Learning By Students Of A University Class. European Scientific Journal December Edition, 8(28), 1857-7881.

[54] Weller, M. (2007). Learning objects, learning design, and adoption through succession. Journal of Computing in Higher Education, 19(1), 26-47. https://doi.org/10.1007/BF03033 $\underline{418}$

[55] Alksasbeh, M. Z., \& Alqaralleh, B. A. Y. (2017). Integrating quality features into technology acceptance model for examining the acceptance of mobile banking. Journal of Theoretical and Applied Information Technology, 95(16), 3737-3748. https://doi.org/10.1186/s 13019-015-0209-x

[56] Gan, C. L., \& Balakrishnan, V. (2018). Mobile Technology in the Classroom: What Drives Student-Lecturer Interactions? International Journal of Human-Computer Interaction, 34(7), 666-679. https://doi.org/10.1080/10447318.2017.1380970 
[57] Lee, D. Y., \& Lehto, M. R. (2013). User Acceptance of YouTube for Procedural Learning: An Extension of the Technology Acceptance Model. Computers \& Education, 61(1), 193208. https://doi.org/10.1016/j.compedu.2012.10.001

[58] Bøe, M. V., \& Henriksen, E. K. (2015). Expectancy-Value Perspectives on Choice of Science and Technology Education in Late-Modern Societies. Understanding Student Participation and Choice in Science and Technology Education, 1-412. https://doi.org/10.1007/9 78-94-007-7793-4

[59] Bøe, M. V., Henriksen, E. K., Lyons, T., \& Schreiner, C. (2011). Participation in science and technology Young people's achievement-related choices in late-modern societies. Studies in Science Education, 47(1), 37-72. https://doi.org/10.1080/03057267.2011.54962 $\underline{1}$

[60] Irvine, J. (2018). A framework for comparing theories related to motivation in education. Research in Higher Education Journal, 35, 1-30. Retrieved from http://www.aabri.com/ copyright.html

[61] Koo, C., Chung, N., \& Nam, K. (2015). Assessing the impact of intrinsic and extrinsic motivators on smart green IT device use: Reference group perspectives. International Journal of Information Management, 35(1), 64-79. https://doi.org/10.1016/j.ijinfomgt.2014.10.001

[62] Park, E., Baek, S., Ohm, J., \& Chang, H. J. (2014). Determinants of player acceptance of mobile social network games: An application of extended technology acceptance model. Telematics and Informatics, 31(1), 3-15. https://doi.org/0.1016/j.tele.2013.07.001

[63] Gefen, D., Straub, D., \& Boudreau, M.-C. (2000). Structural Equation Modeling and Regression: Guidelines for Research Practice. Communications of the Association for Information Systems, 4(7), 1-77. https://doi.org/10.17705/1CAIS.00407

[64] Gikas, J., \& Grant, M. M. (2013). Mobile computing devices in higher education: Student perspectives on learning with cellphones, smartphones \& social media. The Internet and Higher Education, 19, 18-26. https://doi.org/10.1016/j.iheduc.2013.06.002

\section{Authors}

Lillian-Yee-Kiaw Wang is a lecturer in School of Information Technology, Monash University Malaysia, Jalan Lagoon Selatan, Bandar Sunway, 47500 Subang Jaya, Selangor. Her research interests are Cloud e-learning and educational technology.

Sook-Ling Lew is a senior lecturer in Faculty of Information Science and Technology, Multimedia University, Jalan Ayer Keroh Lama, 75450 Melaka. Her research interests include knowledge management (KM), educational technology, e-commerce, image processing and recreational studies.

Siong-Hoe Lau is a professor in Faculty of Information Science and Technology, Multimedia University, Jalan Ayer Keroh Lama, 75450 Melaka. His research interest is in Education Computing \& Technology, Educational Data Mining and HumanComputer Interaction Security (HCISec).

Article submitted 2019-10-14. Resubmitted 2020-01-13. Final acceptance 2020-01-13. Final version published as submitted by the authors. 